\title{
Biological Rhythms Workshop IB: Neurophysiology of SCN Pacemaker Function
}

\author{
S.J. KuHLMAN \\ Cold Spring Harbor Laboratory, Cold Spring Harbor, New York 11724
}

\begin{abstract}
Pacemakers are functional units capable of generating oscillations that synchronize downstream rhythms. In mammals, the suprachiasmatic nucleus ( $\mathrm{SCN}$ ) of the hypothalamus is a circadian pacemaker composed of individual neurons that intrinsically express a near 24-hour rhythm in gene expression. Rhythmic gene expression is tightly coupled to a rhythm in spontaneous firing rate via intrinsic daily regulation of potassium current. Recent progress in the field indicates that SCN pacemaking is a specialized property that emerges from intrinsic features of single cells, structural connectivity among cells, and activity dynamics within the SCN. The focus of this chapter is on how Nature built a functional pacemaker from many individual oscillators that is capable of coordinating the daily timing of essential brain and physiological processes.
\end{abstract}

\section{INTRODUCTION}

The mammalian SCN is a bilateral nucleus that contains approximately 20,000 densely packed neurons and is localized to the hypothalamus, just dorsal to the optic chiasm (Fig. 1). Individual SCN neurons are capable of generating self-sustained oscillations; however, it is the SCN ensemble as a whole that encodes luminance history and generates rhythmic output signals that serve to organize the timing of essential brain and physiological processes. The SCN is considered a pacemaker because it both generates self-sustained oscillations and synchronizes downstream targets to the environmental light/dark cycle. The SCN itself is entrained (synchronized) to the external light cycle via a light-input pathway that directly innervates the SCN. Pacemaking is a specialized property that emerges from intrinsic features of single cells, structural connectivity among cells, and activity dynamics within the SCN. The first section of this chapter focuses on how these three factors interact to produce a functional pacemaker. In the section following, evidence that the SCN is indeed a pacemaker capable of controlling downstream targets is reviewed, and in the final section, the potential physiological significance of circadian timing in animals is discussed.


Figure 1. Day-night difference in ${ }^{14} \mathrm{C}$-labeled deoxyglucose uptake in the SCN. Coronal sections of the rodent brain; arrow points to the bilateral SCN in the hypothalamus. (Left) Daytime glucose uptake is high, as indicated by the strong signal generated from an injection of radioactively labeled glucose into the rodent during the day. (Right) Nighttime glucose uptake is low in animals injected during the night. (Adapted, with permission, from Schwartz and Gainer 1977 [CAAAS].)
The SCN pacemaker is a model system in which one might say that the "black box" has been broken open; we now have the techniques to peer into the black box. A major advance since the 1960 Cold Spring Harbor "Biological Clocks" meeting is that it is now experimentally possible to directly probe mechanisms of pacemaker function.

\section{BUILDING A PACEMAKER}

\section{Coupling the Intracellular Feedback Loop to Overt Output: The Role of Electrical Activity}

A defining characteristic of mammalian SCN neurons is their ability to express a cell-autonomous rhythm in electrical activity. Electrical activity in neurons is produced by the opening of membrane-spanning ion channels, and the opening of these channels changes the voltage of the neuron. There is a voltage threshold (called the spike threshold) that, if reached, causes the neuron's membrane voltage to rapidly depolarize, and the cell is transiently flooded with calcium due to the opening of voltage-sensitive $\mathrm{Ca}^{2+}$ channels. The influx of calcium causes neurotransmitters or neuropeptides to be released from the presynaptic terminal of the neuron. The transient deflection in membrane voltage is referred to as a "spike" and is dependent on $\mathrm{Na}^{+}$ channels that are sensitive to the neurotoxin tetrodotoxin (TTX). SCN cells spontaneously generate spikes, and the frequency at which these spikes are generated varies with time of day. Spike rate (or firing rate) is high during the day and low at night for both nocturnal and diurnal mammals. Blocking expression of electrical activity with TTX in the SCN disrupts circadian behaviors such as locomotor activity (Schwartz et al. 1987); therefore, it is generally accepted that the rhythm in spike rate from the SCN serves to couple the transcription-translation feedback loop that occurs in the SCN to overt behavioral output.

In vivo recordings by Inouye and Kawamura (1979) first revealed the circadian rhythm in electrical activity from populations of SCN neurons. Subsequent work demonstrated that the rhythm in spike rate is self-sus- 
tained and does not require additional synaptic or humoral drive (Green and Gillette 1982; Groos and Hendriks 1982; Inouye and Kawamura 1982; Shibata et al. 1982). Because the generation of circadian rhythms are thought to be based on an intracellular transcription-translation feedback loop (discussed in Part IA), it is predicted that individual SCN cells should be competent oscillators, i.e., the rhythm in firing rate should be cell-autonomous.

In a landmark study, Welsh et al. (1995) provided strong evidence that, indeed, single cells are competent oscillators. Subsequent multielectrode array studies confirmed this finding (Liu et al. 1997; Herzog et al. 1998; Honma et al. 1998). The firing rates of individual SCN neurons dispersed at low density onto multielectrode array dishes can be continuously monitored (Fig. 2A). Dispersed neurons spike spontaneously, and many neurons express a rhythm in the frequency of spontaneous firing, with a period of about 24 hours. Importantly, neurons within the same culture oscillate at different phases and express different circadian periods (Fig. 2A). The most direct evidence for cell-autonomous rhythm generation comes from a nonvertebrate preparation. Completely isolated retinal basal neurons from the marine mollusk Bulla gouldiana express a circadian rhythm in membrane voltage and potassium conductance (Michel et al. 1993).

Our molecular understanding of rhythms generation (discussed in Part IA) provides valuable tools for testing hypotheses of clock function. Genetic mutation of a single clock gene can disrupt rhythmic expression of all clock genes. For example, mice that are heterozyogous for a point mutation in the Clock locus display a lengthening of the circadian period (Vitaterna et al. 1994). If the molecular feedback loop is cell-autonomous, the period of individual cells from the Clock mutant is predicted to also be lengthened as compared to that of wild-type cells (Fig. 2B). Indeed, recordings of SCN neurons dispersed onto multielectrode arrays demonstrated that the period of the rhythm in spontaneous firing rate is longer in mice heterozygous for the Clock mutation than that of wild type (Herzog et al. 1998; Nakamura et al. 2002). Similarly, a mutation in casein kinase $1 \varepsilon$ (called tau) shortens the period of locomotor rhythmicity and also shortens the rhythm in spontaneous firing rate in single SCN neurons (Fig. 2B) (Liu et al. 1997). On the basis of this evidence, it is generally concluded that the intracellular molecular feedback loop imposes rhythmicity to downstream targets outside of the SCN through the expression of a rhythm in the frequency of electrical activity in individual SCN neurons.

\section{Ionic Basis for the Rhythm in Spontaneous Firing Rate}

In this section, we review the physiological basis of the rhythm in spontaneous firing. The key concept here is that the spontaneous rhythm in firing rate is a property intrinsic to individual cells. In subsequent sections, we discuss how these individual cells are wired together and how activity dynamics within the SCN contribute to the SCN's ability to measure time.

Many types of neurons are capable of spontaneously firing spikes in the absence of synaptic transmission
A


B

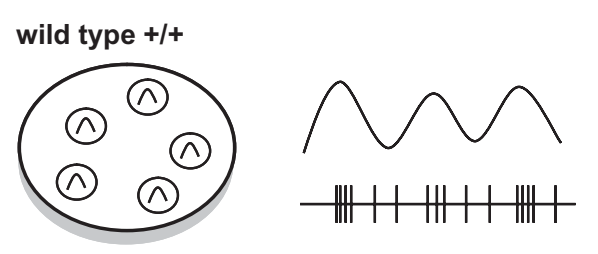

clock point mutation $+/-$
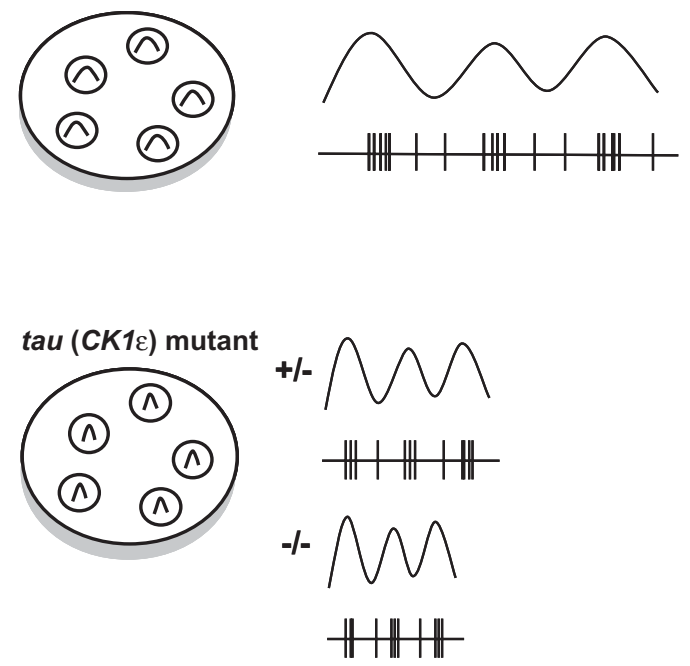

Figure 2. Evidence that the circadian rhythm in spontaneous firing rate of SCN neurons is cell-autonomous. (A) SCN neurons dispersed at low density in multielectrode dishes exhibit a rhythm in spontaneous firing rate. Importantly, the waveforms of individual neurons are not synchronized; thus, circadian rhythmicity does not require cell communication. Vertical lines represent the occurrence of a spike, and the amplitude of the waveform represents spike rate. $(B)$ Mutations in core clock genes alter both the period of locomotor rhythmicity and the period of the rhythm in spontaneous firing rate. Spontaneous firing in wild-type control neurons oscillates with a period of approximately 23.5 hours (top), whereas spontaneous firing in neurons heterozygous for a point mutation in the Clock locus oscillates with a longer period, 25 hours (middle). The period of the spontaneous firing rate rhythm in neurons having only one functional copy of casein kinase $1 \varepsilon(\mathrm{CK} 1 \varepsilon)$ is short, 21 hours, and the firing rate rhythm is even shorter in the homozygous mutant, 19 hours.

(Hausser et al. 2004). The rate of spontaneous activity itself can be bidirectionally modulated, thus providing an additional level of regulation. Within a circuit, the source 


\section{BIOLOGICAL RHYTHMS WORKSHOP IB}

of rate modulation can be synaptic (Nelson et al. 2003; Smith and Otis 2003) or intrinsic in origin, as is the case for SCN neurons (Pennartz et al. 2002; Kuhlman and McMahon 2004).

To produce spontaneous activity, intrinsic currents must interact to depolarize the neuron's voltage to spike threshold, elicit a spike, and repolarize the membrane to a negative potential from which the next spike can be initiated. In other words, the neuron's voltage must fluctuate in a regenerative process. Different cell types use different strategies to generate this regenerative spontaneous activity. For example, in some neurons of the thalamus, the regenerative process results from dynamic recruitment and activation of hyperpolarization-activated channels and T-type $\mathrm{Ca}^{2+}$ channels (McCormick and Huguenard 1992). In other neurons of the cerebellum, persistent $\mathrm{Na}^{+}$currents are essential for regenerative spontaneous firing (Raman et al. 2000; Taddese and Bean 2002; Do and Bean 2003).

SCN neurons are unique compared to other neuron types; in addition to firing spontaneously, the rate of spontaneous firing is modulated in a rhythmic manner. Therefore, there are two distinct aspects of spontaneous spike activity in SCN neurons that must be addressed: (1) the identification of processes that drive the daily rhythm in spike rate and (2) the identification of ion channels that contribute to the regenerative process that underlies spontaneous firing in general. Indeed, there are two dissociable mechanisms. One mechanism-the subthreshold regulation of resting membrane potential and basal potassium conductance - is likely the primary driver of the rhythm in spike rate. The second mechanism - regulation of suprathreshold spike-associated conductances mediated by channels such as voltage-dependent potassium channels - facilitates regenerative spontaneous firing and determines the shape of the spike waveform (Fig. 3).

Circadian rhythm in subthreshold basal potassium conductance. During the night phase, SCN neurons are hyperpolarized relative to neurons during the day phase (de Jeu et al. 1998; Schaap et al. 1999; Pennartz et al. 2002; Kuhlman and McMahon 2004). Daily hyperpolarization is accompanied by an increase in potassium ion conductance (i.e., more potassium channels are open during the night). Importantly, the rhythms in membrane potential and basal potassium conductance are maintained in constant dark conditions (Kuhlman and McMahon 2004).

How do these changes contribute to the rhythm in firing rate? An increase in potassium conductance during the night drives the resting membrane potential closer to


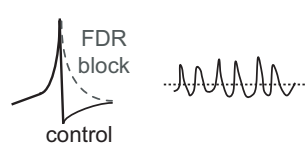

spike-associated conductances
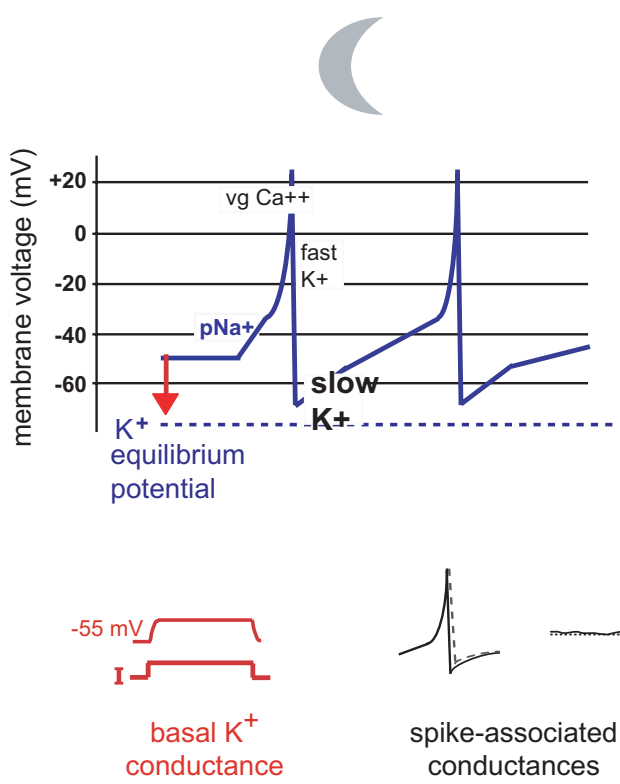

Figure 3. A model of the ionic basis for the circadian rhythm in spontaneous firing rate. (Top) The voltage trajectory of the membrane potential (blue) fluctuates in a regenerative manner due to the opening and closing of voltage-dependent spike-associated conductances (black type) during the day $($ left $)$ and night $(r i g h t)$. Persistent $\mathrm{Na}^{+}$channels $\left(\mathrm{pNa}^{+}\right)$continuously exert a depolarizing force toward spike threshold. Once spike threshold is reached, voltage-gated $\mathrm{Na}^{+}$channels and $\mathrm{Ca}^{2+}\left(\mathrm{vg} \mathrm{Ca}^{2+}\right)$ channels open, causing the neuron to "spike." The membrane potential repolarizes due to the opening of fast-delayed rectifier $\mathrm{K}^{+}$channels (fast $\mathrm{K}^{+}$, FDR) and slower acting $\mathrm{K}^{+}$channels (slow $\mathrm{K}^{+}$), the voltage-gated $\mathrm{Na}^{+}$and $\mathrm{Ca}^{+2}$ channels close before the next spike is initiated. Conductance through some channels is dependent on time of day: (bold, large type) high conductance; (small type) low conductance. (Bottom) Experimentally quantified daily changes in ionic conductances. There is a daily change in membrane potential $(\Delta 10 \mathrm{mV})$, as predicted by the model. Additional evidence for daily rhythm in basal $\mathrm{K}^{+}$conductance comes from the following observation: For the same current (I) injected into a cell, the voltage deflection is large during the day, a signature that basal $\mathrm{K}^{+}$channels are closed (low conductance), whereas the voltage deflection is small during the night, a signature that basal $\mathrm{K}^{+}$channels are opened (high conductance). The properties labeled in red are believed to underlie the rhythm in spike rate. Spike-associated conductances (indicated in black) enable the neuron to express a rhythm in spontaneous firing rate. Blockade of FDR conductances during the day broadens the spike (dashed lines), whereas blockade at night has no effect. Fast membrane potential oscillations mediated by L-type $\mathrm{Ca}^{2+}$ channels hover around spike threshold (dotted line) and are expressed only during the day. These transient $\mathrm{Ca}^{2+}$ channel openings may facilitate high firing rates or perhaps promote increased $\mathrm{Ca}^{2+}$ entry during the day. 
the equilibrium potential for potassium ions (Fig. 3, red arrow), which is hyperpolarized relative to the resting membrane potential and pulls the cell's voltage further away from spike threshold. Thus, increased potassium conductance is expected to decrease spike rate. Additionally, low input resistance (high conductance) means that the voltage deflection in response to a given level of stimulation is small, compared to the same level of stimulation applied to a neuron with higher input resistance (Fig. 3). The daily depolarization in membrane voltage is thought to drive the rhythm in spike rate due to decreased potassium conductance. However, the specific potassium channels that underlie this daily change remain to be identified.

Spike-associated conductances. SCN neurons express a complement of ionic currents that generate spontaneous firing at rates up to $10-15 \mathrm{~Hz}$ during the day phase. As stated earlier, the voltage trajectory of the neuron must follow a regenerative process for spontaneous activity to be maintained. Many specific channels mediating this function have been identified in SCN neurons, and in some cases, it has been determined that the channels are modulated in a rhythmic manner.

One requirement for regenerative spiking is the presence of an intrinsic drive to bring the neuron to spike threshold. In SCN neurons, slowly inactivating, persistent sodium channels contribute to drive the cell to threshold (Pennartz et al. 1997; Jackson et al. 2004; Kononenko et al. 2004). It is unlikely that these currents are regulated in a circadian manner, although diurnal modulation by cAMP is possible (Kononenko and Dudek 2006). A second intrinsic drive to threshold may come from a depolarizing oscillation in $\mathrm{Ca}^{2+}$ conductance. Pennartz et al. (2002) identified the presence of TTX-resistant, high-frequency $\mathrm{Ca}^{2+}$ oscillations $(2-8 \mathrm{~Hz})$ that are mediated by Ltype $\mathrm{Ca}^{2+}$ channels. These oscillations cause the membrane voltage to rapidly fluctuate around spike threshold and are regulated in a diurnal manner, present during the day phase only (Fig. 3). The daytime depolarized membrane voltage described in the earlier section also brings the cell closer to spike threshold, which, together with the high input resistance state, means that small changes in $\mathrm{Ca}^{2+}$ currents can have a large impact on the voltage trajectory. Therefore, the circadian rhythm in subthreshold basal potassium conductance and spike-associated mechanisms functionally complement one another. However, experimentally, the two mechanisms can be dissociated, demonstrating that they are distinct mechanistically. Suppression of fast $\mathrm{Ca}^{2+}$ oscillations by L-type channel blockade does not disrupt the rhythm in basal potassium conductance (Pennartz et al. 2002). The reciprocal experiment - testing whether the rhythm in L-type $\mathrm{Ca}^{2+}$ channel-mediated fast oscillations persists in the absence of the rhythm in basal $\mathrm{K}^{+}$conductance- has not been done because it requires the identification of the precise channels that underlie the rhythm in basal $\mathrm{K}^{+}$conductance. Nonetheless, the above experiment is sufficient to conclude that circadian regulation of subthreshold basal $\mathrm{K}^{+}$conductance and spike-associated conductances are distinct processes.

A second requirement for regenerative spiking is a suf- ficiently rapid repolarization to ensure brief interspike intervals. Rapidly activating voltage-gated potassium channels subserve this function and have been characterized in SCN neurons (Bouskila and Dudek 1995). Recently, a fast-delayed rectifier (FDR) potassium current in SCN neurons was identified that is regulated in a rhythmic manner (Itri et al. 2005). Blockade of this channel has a significant effect on spike shape specifically during the day (Fig. 3), and FDR channel function is required for the expression of rhythmic spontaneous spike activity.

\section{Phase Shifts: Perturbation of the Transcription- Translation Feedback Loop}

Before moving on to discuss structural connectivity among cells, we first review the physiology of resetting, because mechanisms of phase-shifting are believed to underlie entrainment and are therefore critical for pacemaker function. As briefly mentioned in Part IA, the transcription-translation feedback loop can be reset by light-mediated trans-activation of key clock genes such as Period1 (Perl). Light is the primary entraining agent of the $\mathrm{SCN}$ pacemaker, and photic information is directly conveyed to the SCN by axons projecting from intrinsically photosensitive retinal ganglion cells (ipRGCs) (for review, see Berson 2003). Nocturnal light pulses initiate a signaling cascade that ultimately results in the stable shift (resetting) of the transcription-translation feedback loop via several calcium-dependent signaling pathways that lead to the phosphorylation of the cAMP response elementbinding (CREB) protein, which binds to cAMP response elements (CRE) in the promoter region of responsive genes (e.g., Perl) to activate their expression (Morse and Sassone-Corsi 2002; Dziema et al. 2003). Thus, the light-input pathway regulates transcription of core clock genes via cis-response elements that are distinct from CLOCK/BMAL1-binding response elements (Fig. 4A).

Again, electrophysiological methods were used to verify specific predictions of the transcription-translation feedback loop model. Because light pulses are capable of activating core clock gene expression, it was predicted that the firing rate should also be reset in those cells that receive the phase-shifting light pulse. Indeed, it was demonstrated that the neurons in which Perl is specifically induced by light also have elevated firing rates (Kuhlman et al. 2003). In fact, as expected, a tight correlation between Perl activation and neuronal firing rate exists in entrained conditions (Fig. 4B). In both long days (14 hours light:10 hours dark [14:10 LD]) and balanced days (12:12 LD), firing rate correlates well with levels of Perl promoter activity on a cell-by-cell basis (Quintero et al. 2003; Kuhlman and McMahon 2004). What other predictions of the transcription-translation feedback model can be tested?

It is worth noting that resetting and rhythms generation are generally thought of as two distinct processes. However, as depicted in Figure 4A, the two processes ultimately converge at the level of gene transcription. Thus, agents that are experimentally classified as input/resetting agents may in fact have a potent role in rhythms generation, particularly if such agents are rhyth- 
A

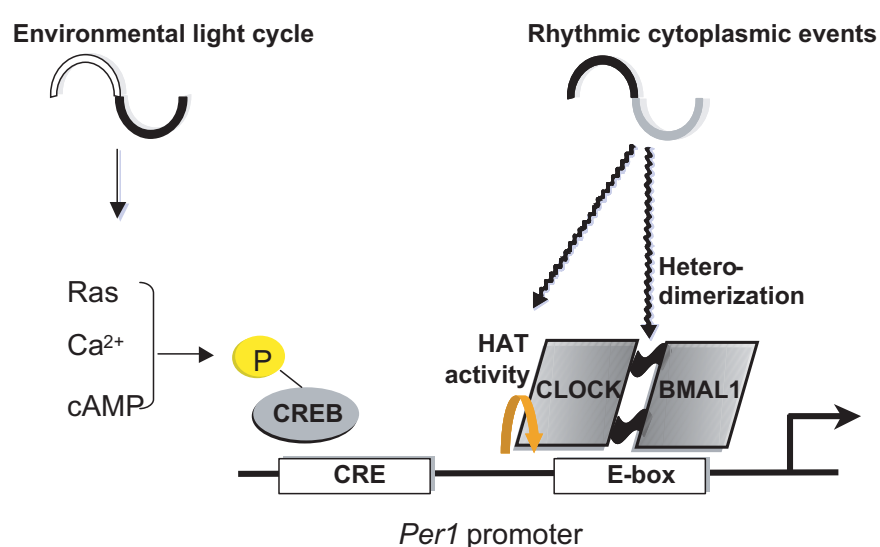

B

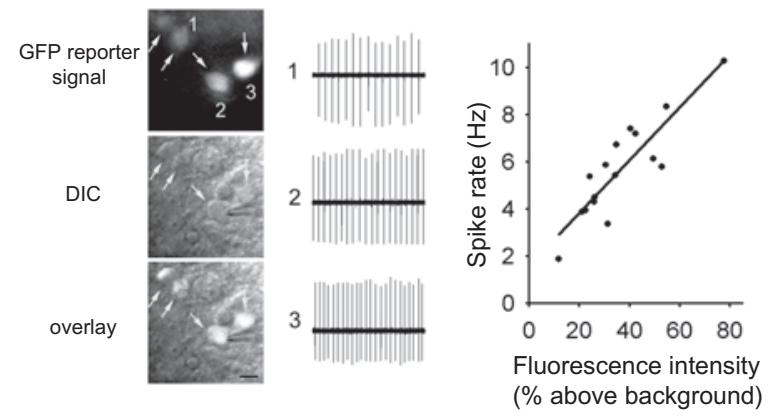

Figure 4. Periodl trans-activation is tightly coupled to spike output. (A) Period1 gene transcription can be activated via the binding of phosphorylated CREB to cAMP response elements (CREs) or the binding of CLOCK-BMAL1 heterodimers to E-box response elements within the Period1 promoter. The CLOCK protein itself possesses histone acetyltransferase (HAT) activity. High HAT activity relaxes chromatin structure, thus promoting increased transcription (see also Fig. 8 in Part IA). (B) Regardless of the route of activation, the level of Periodl trans-activation is correlated with firing rate on a cell-by-cell basis. The level of GFP (green fluorescent protein) reporter intensity (top panel) correlates with spike rate (right column): Cell 1, low intensity, fires at a rate of $1.5 \mathrm{~Hz}$, whereas cell 3, high intensity, fires at a rate of $5 \mathrm{~Hz}$. Shown here are neurons from an acutely prepared SCN slice during the day. Neurons are visualized for recording using differential interference contrast (DIC) microscopy; the recording pipette is patched onto cell 2 (middle panel). The digital intensity image is overlaid with the DIC image (bottom panel). Similar correlations are reported in acutely prepared SCN after a phase-shifting light pulse (not shown). Bar: $10 \mu \mathrm{m}$, trace 10 seconds. mically expressed during normal intact conditions. Likewise, agents that are classified as output signals can also feed back via input pathways to promote high-amplitude rhythms generation (Nitabach et al. 2002; Yamaguchi et al. 2003; Aton et al. 2005; Lundkvist et al. 2005; Maywood et al. 2006). We present Figure 5 as a tool to help visualize this concept. The clock system can be potentially viewed as a network of coupled oscillators, each oscillation producing an output (or coupling signal) that then feeds into another oscillator to promote highamplitude (and reliable) rhythms generation.

Such a view may help to conceptualize the following experimental findings: Coupling between oscillators within the SCN is dependent on VIP (vasoactive intestinal polypeptide) signaling (Cutler et al. 2003; Aton et al. 2005; Maywood et al. 2006) and electrical activity (Yamaguchi et al. 2003). In the absence of VIP signaling, the phase relationship among oscillators breaks down, and individual oscillators become desynchronized from one another. Furthermore, it appears that the number of competent oscillators decreases in the absence of VIP signaling, indicating that in some cell types, VIP signaling is required for rhythms generation. Thus, an emerging model in the field is that in order for intracellular rhyth-



Figure 5. Oscillations are coupled. Output signals, such as electrical activity or signaling molecules (VIP in this example), serve as input signals to neighboring cell oscillators. Likewise, it is possible that within a cell, oscillations are coupled by signaling products of calcium-dependent G-protein-coupled pathways such as cAMP. 
micity to remain self-sustained in the intact system, the transcription-translation feedback loop likely requires oscillations in biochemical signaling to reenforce highamplitude rhythmicity.

Interestingly, an alternative E-box-binding transcription factor complex, NPAS2/BMAL1, can contribute to rhythms generation in SCN neurons under some conditions (Debruyne et al. 2007). In vitro, NPAS2/BMAL1 heterodimer transcriptional activation is sensitive to NADP(H) redox states (Rutter et al. 2001). Given that SCN cells exhibit a robust circadian rhythm in glucose uptake (see Fig. 1) (Schwartz and Gainer 1977), changes in metabolic activity could potentially regulate clockwork gene expression via redox-sensitive transcription factors (Rutter et al. 2002).

\section{Structural Connectivity}

Input. The photopigment melanopsin is expressed in about $3 \%$ of retinal ganglion cells and is responsible for converting the energy of photons to an intracellular chemical signaling cascade capable of depolarizing the ganglion cell to spike threshold. This small subset of retinal ganglion cells projects their axons to the $\mathrm{SCN}$, forming what is called the retinal-hypothalamic tract (RHT, Fig. 6) (for review, see Moore 1996). RHT terminals release both pituitary adenylate-cyclase-activating polypeptide (PACAP) and glutamate. Stimulation of the RHT depolarizes SCN neurons; thus, PACAP and glutamate are considered to be excitatory in the SCN (for review, see Coogan and Piggins 2004). The rate of spike output from the light-sensitive ganglion cells is linearly related to luminance level. Thus, melanopsin ${ }^{+}$retinal ganglion cells represent an early stage of luminance coding and transduce information to the SCN regarding ambient lighting conditions that the animal encounters in the environment. RHT terminal density is highest in the ventral SCN. It is important to note that the RHT is not the sole afferent input carrying photic information to the SCN. There is input from the geniculohypothalamic tract (GHT) originating from the intergeniculate leaflet (IGL), the pretectum (Mikkelsen and Vrang 1994), and serotonergic projections originating from the midbrain median Raphe nucleus (Morin et al. 2006) that indirectly convey photic information in addition to internal brain-state information.

Connectivity within the SCN. To understand neuronal wiring within the $\mathrm{SCN}$, one must appreciate that the SCN is composed of heterogeneous cell types (Fig. 6) for review, see Antle and Silver 2005). The SCN can be organized into two loosely define regions (Abrahamson and Moore 2001): (1) the vetrolateral or core region and (2) the dorsomedial or shell region. Neurons expressing VIP and gastrin-releasing peptide (GRP) are located primarily in the ventrolateral region and generally receive RHT input in addition to input from internal sources, whereas neurons expressing arginine vasopressin (AVP) are located in the dorsomedial region and receive input from internal brain nuclei, including limbic, hypothalamic, and brain stem areas. Most, if not all, SCN neurons express

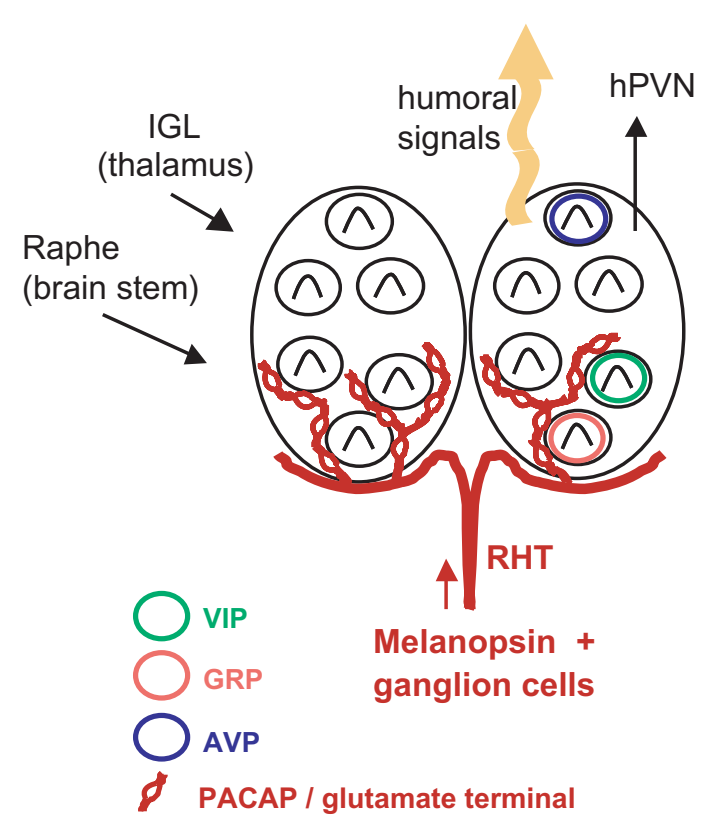

Figure 6. SCN input and output pathways. Light information reaches the SCN directly via the RHT, which is composed of melanopsin-positive ganglion cell axon fibers from the retina, and also indirectly via input from the Raphe nucleus and IGL. The SCN sends GABAergic output to the hPVN, among other targets (see Fig. 8), in addition to releasing diffusible humoral output signals such as TGF- $\alpha$ and prokineticin 2. Not all SCN neurons are directly retinorecipient, the RHT preferentially innervates VIP- and GRP-positive neurons. (VIP) Vasoactive intestinal polypeptide; (GRP) gastrin-releasing peptide; (AVP) arginine vasopressin; (PACAP) pituitary adenylate-cyclaseactivating polypeptide; (RHT) retinal-hypothalamic tract; (hPVN) hypothalmic parventricular nucleus; (IGL) intergeniculate nucleus.

GABA ( $\gamma$-amino- $n$-butyric acid) as their neurotransmitter (Moore and Speh 1993).

Communication between the core and shell subdivisions is mediated by axonal projections from the core to shell (Abrahamson and Moore 2001). The extent to which the shell communicates with the core is unknown. When core VIP or GRP neurons are activated, their terminals most likely release VIP or GRP and the inhibitory neurotransmitter GABA (for review, see Aton and Herzog 2005). Indirect evidence suggests that GABA release from the core to the shell is required for entrainment (Albus et al. 2005). However, direct demonstration using electrophysiological recording methods that SCN cells communicate with one another via GABAergic synapses is lacking.

Local communication among cells is potentially mediated by GABAergic transmission (Strecker et al. 1997) and gap junctions (Long et al. 2005). However, the specifics of how this communication gives rise to the patterns of activity dynamics observed in the SCN (described in the next section) are not well understood. For example, the relative proportion of GABAergic inputs that a single SCN neuron receives from within the SCN versus from outside the SCN is unknown. Furthermore, the functional relevance of gap-junction-mediated electrical coupling is unknown. To ultimately understand pacemaker function, 
future studies are needed to map out the functional wiring among distinct SCN cell types. Fortunately, the tools and techniques to do this are in existence.

Output. Here, we briefly highlight some outputs of the SCN to emphasize that as a population, SCN neurons are not functionally equivalent in terms of signaling to downstream targets (for a complete description of SCN projections to other brain regions, see Saper et al. 2005). For example, a subset of SCN neurons sends GABAergic axon projections to the hypothalamic paraventricular nucleus (hPVN) (Buijs and Kalsbeek 2001), whereas VIP neurons project to gonadotropin-releasing hormone neurons $(\mathrm{GnRH})$ to regulate the timing of the luteinizing hormone (LH) surge (for review, see de la Iglesia and Schwartz 2006).

In addition to structural outputs, some SCN neurons release humoral factors, including transforming growth factor (TGF- $\alpha$ ) and prokineticin 2 (Kramer et al. 2001; Cheng et al. 2002). Humoral release of signaling molecules represents an important mechanism for regulating downstream targets, as demonstrated by a classic study by Silver et al. (1996). Encapsulated SCN transplants maintain the capacity to restore behavioral rhythmicity in SCN-lesioned hosts (Silver et al. 1996). Thus, from these studies and others (Buijs et al. 2006), converging evidence indicates that $\mathrm{SCN}$ neurons regulate multiple downstream targets in the brain, raising the possibility that distinct cells types target and regulate distinct organs and downstream processes (Buijs and Kalsbeek 2001). It is interesting to speculate that such an organization allows for the sequential regulation of differentially timed internal physiological processes.

\section{Dynamics: Constructing a Pacemaker from Many Oscillating Parts}

In the previous sections, we discuss how to build individual oscillators using a molecular feedback loop and ion channels; we also discuss how these oscillators are connected to the rest of the brain. Now we discuss how to put the oscillators together to form a functional pacemaker. To address this issue requires that the waveforms of many oscillators must be simultaneously monitored within the SCN ensemble. Technically, this can has been accomplished using (1) mutlielectrode arrays to monitor firing rate of individual cells (Herzog et al. 1997; Nakamura et al. 2001), (2) multiunit electrophysiological recordings (Mrugala et al. 2000; Schaap et al. 2003; Vansteensel et al. 2003), and (3) transgenic reporter mice and rats harboring clock-gene-driven fluorescent (Kuhlman et al. 2000) or bioluminescent (Yamazaki et al. 2000; Yamaguchi et al. 2001; Wilsbacher et al. 2002; Yoo et al. 2004) reporters of circadian gene activity for real-time imaging of circadian gene expression.

On the basis of the diagram in Figure 4A, one may guess that because the cis-response elements for both entrainment (i.e., CRE) and rhythms (i.e., E box) generation coexist in single cells, entrainment is cell-autonomous. In other words, each oscillator is predicted to have the ability to detect and respond to light input and shift the transcription- translation feedback loop accordingly. However, not all SCN neurons receive direct input from the RHT. Therefore, not surprisingly, the response to light is diverse among cells, both in firing rate (Meijer et al. 1998; Kuhlman et al. 2003) and in Perl induction (Yan et al. 1999; Albus et al. 2005; Nakamura et al. 2005); the light pathway preferentially activates the retinorecipient region of the SCN. Furthermore, there is substantial evidence that the rhythms expressed by SCN tissue as a whole are a composite of single-cell rhythms that are narrower in waveform and distributed across the day (Fig. 7A). The time of peak electrical and peak transcriptional activity varies among cells, and individual cell waveforms are not synchronized to a single, average waveform (Quintero et al. 2003; Schaap et al. 2003; Yamaguchi et al. 2003; Inagaki et al. 2007). In fact, it has been directly observed that light input is capable of reorganizing the phase relationship among individual oscillators (Quintero et al. 2003; Inagaki et al. 2007). These observations suggest that mammalian entrainment is an emergent property and requires distinct coupling mechanisms among SCN neurons.

In addition to functioning as a circadian pacemaker, the SCN also functions as a seasonal clock capable of encoding day length (Sumova et al. 1995, 2003; Messager et al. 1999; Mrugala et al. 2000; Nüsslein-Hildesheim et al. 2000; Schaap et al. 2003). A major target of the SCN's seasonal output is the pineal gland. This gland releases melatonin during the night, and the duration of nighttime release reflects photoperiod length. One mechanism by which the SCN encodes day length appears to be via regulating phase relationships among individual SCN neurons (Inagaki et al. 2007; VanderLeest et al. 2007). In short days (8:16 LD), peak times of firing activity are relatively synchronized, restricted to a narrow temporal window. In contrast, in long days (16:8 LD), peak times are broadly distributed (Fig. 7B). Similarly, peak times of gene expression depend on photoperiod length (Inagaki et al. 2007).

To establish that the SCN is truly encoding day length by the phase relationship among oscillators, versus passively reflecting luminance history as an epiphenomenon, phase reorganization must be reflected in a downstream target, e.g., the behavioral rhythm in locomotor activity. A recent study in which single-cell waveforms of Perl activation were monitored from a cohort of animals that express three different behavioral states provides additional confirmation that phase reorganization is behaviorally relevant (Ohta et al. 2005). Ohta et al. (2005) used constant light to induce three different behavioral states in the cohort; individual animals exhibited either (1) longperiod locomotor activity, (2) arrhythmic locomotor activity, or (3) "split" locomotor activity in which the animal displayed two distinct times of wheel-running behavior in 24 hours. The phase distribution of oscillating neurons did indeed correlate with the behavioral state of the animal (Fig. 7C). Importantly, the animals in this experiment were exposed to the same light stimulus, avoiding confounds of "masking," in which light directly reduces locomotor activity independent of daily rhythmicity.

The results of Ohta et al. (2005) also demonstrate the importance of assaying rhythmicity at the level of the functional unit of rhythms generation (the single cell) in 
A

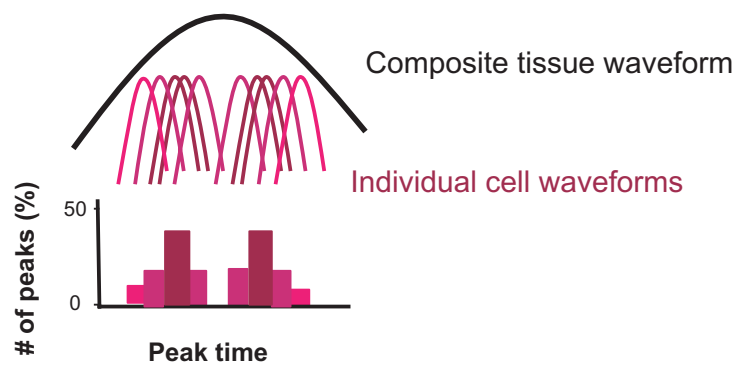

B
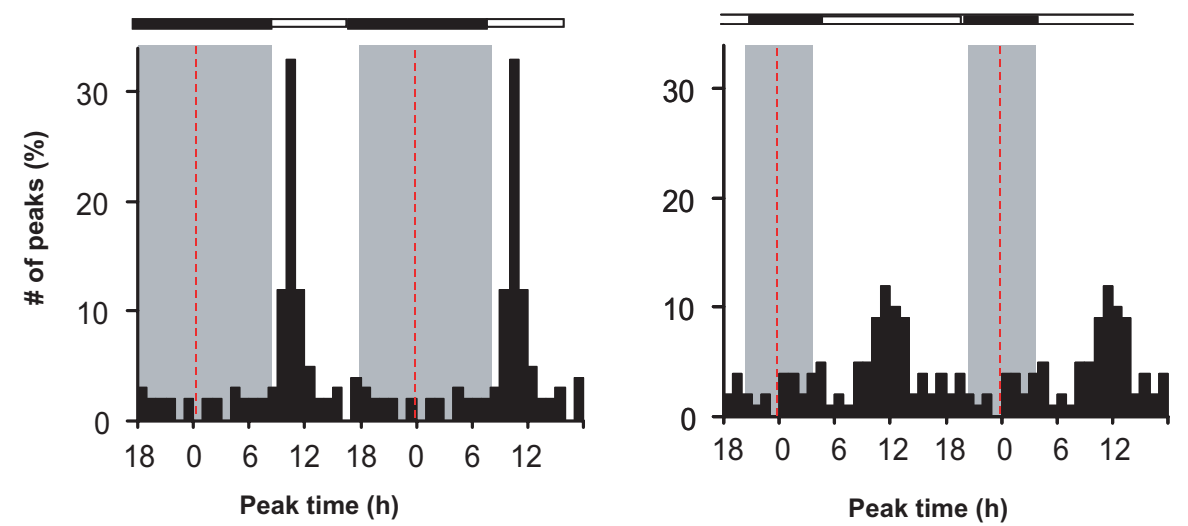

C

\Left hemi SCN

I Right hemi SCN
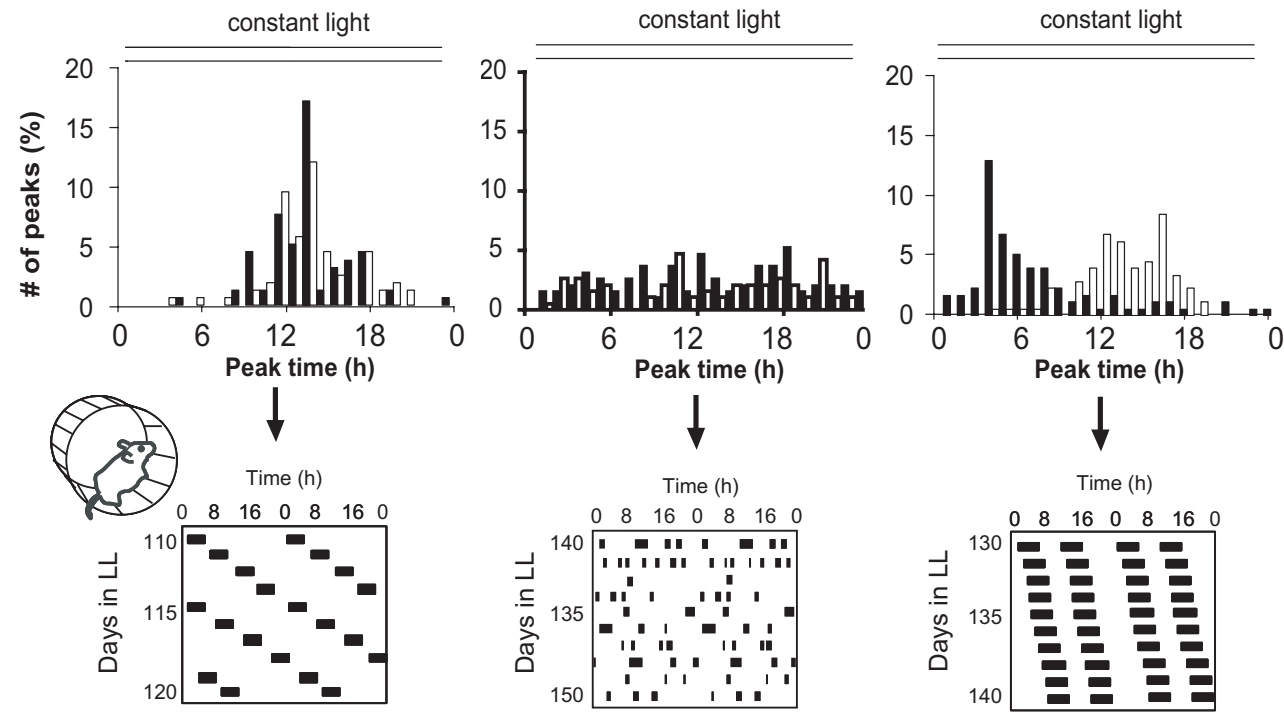

Figure 7. Phase diversity among SCN neurons encodes day length. $(A)$ The composite waveform of SCN tissue, as measured by tissue-level in situ hybridizations for clock gene mRNAs or as measured by multiunit recording of the electrical activity of many neurons, is actually composed of individual cell waveforms that are narrower in width than the population waveform. The waveform distribution can be easily represented in a histogram plot of peak times (bottom plot). (B) The peak times of electrical activity waveforms of SCN neurons are narrowly distributed in short days. However, the distribution is experience-dependent and broadens when animals are housed in long days. Peak times, in hours (h), are plotted relative to midnight (red vertical dashed line). (Adapted, with permission, from VanderLeest et al. 2007 [@ Elsevier].) (C) Variations in phase distribution are reflected in animal behavior. Constant light induces three distinct behavioral states: long period (bottom, left), arrhythmic (bottom center), or "split" (bottom right). The peak times of Period 1 reporter waveforms redistribute in a manner consistent with behavior. Peak times, in hours (h), are plotted relative to time in vitro. (Adapted, with permission, from Ohta et al. 2005 [@Nature Publishing Group].)

addition to measuring rhythmicity at the population level. Previous studies examining the effects of constant light (LL) on SCN tissue as a whole demonstrated that LL induces arrhythmicity in electrical activity and gene expression (Shibata et al. 1984; Mason 1991; Beaule et al. 2003; Sudo et al. 2003). On the basis of the results of Ohta et al. (2005), we can now interpret these earlier findings to mean that LL induces desynchrony among individual 
oscillators, rather than arrhythmicity of molecular oscillations (see also Fig. 2 in Kuhlman et al., this volume). Individual cells remain rhythmic under LL conditions.

Phase heterogeneity among individual oscillator cells is not limited to mammalian pacemakers. Studies from the laboratory of Michael Rosbash demonstrate that the phase relationship among individual oscillator cells contributes to encoding day length in Drosophila (Stoleru et al. 2005, 2007). Although the full physiological significance of phase diversity among pacemaker cells remains to be fully investigated, the evidence to date demonstrates that coupling among oscillator cells is a substrate for encoding day length.

\section{HIERARCHICAL ORGANIZATION OF BODY OSCILLATORS}

Many tissues and organs within the body display circadian rhythms in gene expression and in secretion of signaling molecules. Strikingly, when isolated in culture, many of these oscillations continue. Examples of such peripheral "clocks" are depicted in Figure 8. The SCN is considered a pacemaker capable of synchronizing peripheral oscillations due to the following evidence: (1) Classic transplant and lesion studies, such as the work of Ralph at al. (1990). In this 1990 study, SCN tissue was transplanted from casein kinase $1 \varepsilon$ mutant hamsters (tau) into SCN-lesioned wild-type hosts, and the host animal's locomotor rhythm took on the donor's period (Ralph et al. 1990). (2) Circadian rhythms in corticosterone (Moore and Eichler 1972), locomotor and drinking behavior (Stephan and Zucker 1972), and body temperature

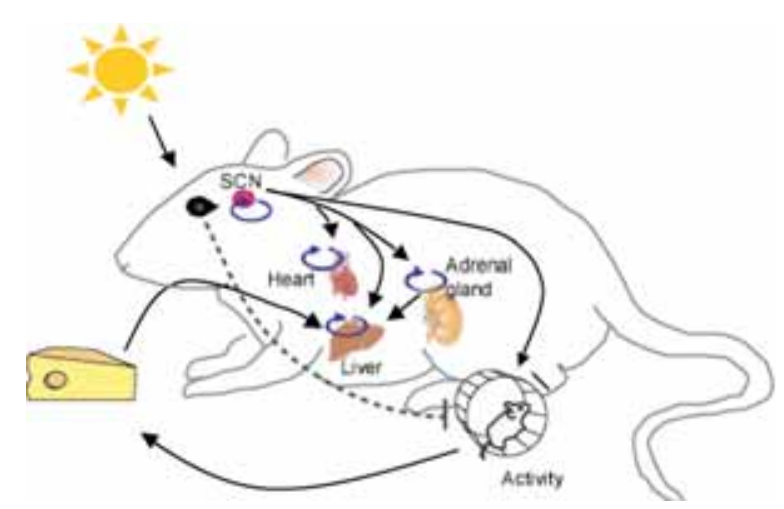

Figure 8. Hierarchical organization of body clocks. Many tissues throughout the body continue to oscillate for a few cycles when isolated in vitro; however, the oscillations eventually dampen. The SCN is generally considered to be the primary organizer of peripheral body oscillators, functioning to coordinate timing among the various tissue oscillators and to synchronize oscillations among the cell-autonomous oscillators within a given tissue. Importantly, there is a food-entrainable oscillator that is maintained in SCN-lesioned animals exposed to a feeding schedule in constant darkness. Feedback likely involves glucocorticoid release from the adrenal gland into the bloodstream that is then sensed in brain regions outside of the SCN (feedback not shown). In the intact system, the food-entrainable oscillator and the SCN oscillate in a coordinated manner due to SCN regulation of locomotor activity; the animal will only eat when it is awake, timed primarily by the SCN.
(Refinetti et al. 1994) are lost in SCN-lesioned animals.

Cues from the SCN are hypothesized to coordinate the timing of peripheral clocks and to impose cellular synchrony within a given tissue. As a test of this hypothesis, peripheral tissues were isolated and cultured from SCNlesioned animals. As expected, it was found that tissues oscillated out of phase with one another. However, within a given tissue, it was found that oscillations among individual cells were coherent, contrary to expectations (Yoo et al. 2004), suggesting the presence of organ-specific synchronizers (Stratmann and Schibler 2006). This later result could be an artifact of the dissection and culturing procedure. It has been demonstrated that changing culture medium is sufficient to reset desynchronized rhythms. Therefore, the presence of coherent oscillations in vitro does not necessarily mean that cells were coherent in vivo. To further explore the role of the $\mathrm{SCN}$ in regulating cellular synchrony within a tissue, Guo et al. (2006) examined Per 1:Bmal1 mRNA expression ratios in SCNlesioned and control animals. Perl and Bmall oscillate $180^{\circ}$ out of phase from each other; therefore, if there is cellular synchrony within a tissue, one would expect to find a large peak in the Per 1:Bmal ratio during the course of a cycle. In control animals, the Per1:Bmall ratio attained a large value during the course of 24 hours, signifying coherence among cellular oscillators. In contrast, the Per1:Bmall ratio did not attain a large value in SCNlesioned animals, signifying desynchrony among cellular oscillators (Guo et al. 2006). Taken together, the evidence indicates that cues from the SCN coordinate the timing of peripheral clocks and impose cellular synchrony within a given peripheral tissue.

The SCN is not the only brain circuit capable of synchronizing internal physiology to environmental cycles. When rodents are housed in a light cycle and given restricted food access during the day so that the time of feeding is out of phase with the time they would normally be active and eat, the presence of a food-entrainable oscillator is revealed (Damiola et al. 2000; Stokkan et al. 2001). The food-entrainable circuit includes the following brain areas: the subparaventricular zone (Abrahamson and Moore 2001; Deurveilher and Semba 2005), dorsomedial nucleus of the hypothalamus, and paraventricular nucleus of the hypothalamus (see Fig. 8) (Gooley et al. 2006; Mieda et al. 2006). The food-entrainable oscillator regulates rhythmic expression of metabolic enzymes in the liver, thus "priming" internal physiology for food intake (Buijs et al. 2006). Under normal conditions, the SCN's ability to regulate locomotor activity ensures that the animal will eat during its waking phase; therefore, the $\mathrm{SCN}$ can be viewed as indirectly coordinating liver metabolism with other body oscillations via behavior. The rhythm in liver metabolism may itself reenforce robust rhythmicity via regulating redox state and NPAP2/BMAL1 transcriptional activity (Rutter et al. 2001, 2002).

Importantly, although there is a hierarchical organization, regulation of body clocks is not unidirectional. There are multiple feedback pathways to the brain, including sensitivity to blood-borne hormones by the arcuate nucleus that projects to the SCN (Fig. 9). Functionally, it 
has been demonstrated that sleep state modulates the firing rate of SCN neurons, perhaps via input from the Raphe nucleus (Deboer et al. 2003).

\section{PHYSIOLOGICAL SIGNIFICANCE OF THE SCN PACEMAKER: TEMPORAL ORGANIZATION OF INTERNAL PHYSIOLOGY}

The SCN serves to temporally organize a diverse range of physiological processes, including metabolism, growth, and cortical arousal. It is speculated that such coordination allows multicellular organisms to optimize performance during waking and to optimize tissue repair and memory consolidation during sleep. The SCN achieves this regulation via output pathways (Fig. 9A). Prominent output pathways include projections to the subparaventricular zone (sPVZ) located just dorsal to the $\mathrm{SCN}$, the hypothalmic paraventricular nucleus (hPVN), the dorsomedial hypothalamus (DMH), and the arcuate nucleus (Arc) (for review, see Hungs and Mignot 2001; Saper et al. 2005).

The hPVN relays SCN signals to the autonomic nervous system via distinct sympathetic-parasympathetic pathways. Corticosterone release from the adrenal cortex located just above the kidney is regulated by the sympathetic pathway (Fig. 9A, highlighted light green). Temporal regulation of rate-limiting metabolic enzymes in the liver, including cytochrome P450s, heme biosynthesis, and mitochrondial function, is mediated in part via the parasympathetic pathway (Fig. 9A, highlighted dark green) (for review, see Hungs and Mignot 2001; Saper et al. 2005; Buijs et al. 2006). The hPVN also relays SCN signals to the pineal gland to produce rhythmic release of melatonin during the night (not shown in Fig. 9A).

In addition to regulating food uptake via a pathway to the hPVN as described in the previous section, the DMH

A

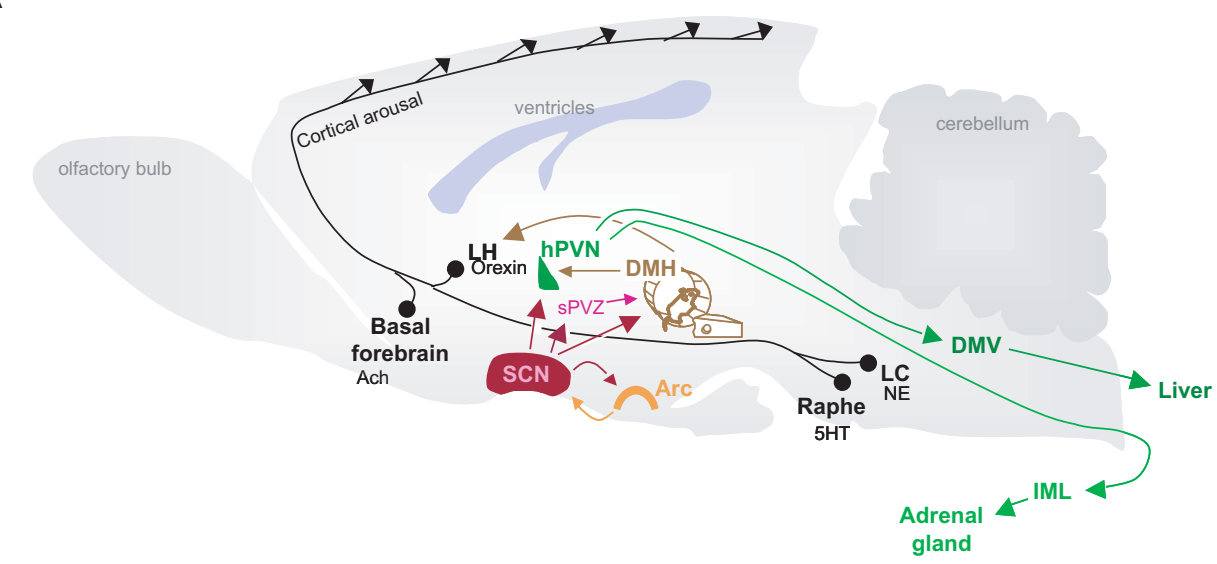

B


Figure 9. Physiological significance of SCN output signals: Coordination of body metabolism to optimize performance during waking. (A) The SCN (red) sends extensive projections to the paraventricular nucleus of the hypothalamus (green, hPVN), subparaventricular zone (pink, sPVZ), and dorsomedial hypothalamus (brown, DMH). The body is likely "primed" for food intake during the day via the $\mathrm{SCN} \rightarrow \mathrm{SPVZ} \rightarrow \mathrm{DMH} \rightarrow \mathrm{hPVN}$ circuit that ultimately regulates synthesis and secretion of corticosterone from the adrenal cortex and glucose production in the liver. Cortical arousal is regulated in part via the SCN $\rightarrow \mathrm{DMH} \rightarrow \mathrm{LH}$ circuit. The SCN is reciprocally connected with the arcuate nucleus (Arc). The Arc contains receptors responsive to blood-borne hormones and therefore represents a key feedback pathway to the SCN. The SCN also receives input from other brain areas and thus functions as an integrator of both environmental and internal signals. (DMV) Dorsal motor nucleus of the vagus; (IML) intermediolateral column of spinal cord; (LC) locus coeruleus; (LH) lateral hypothalamus; (Raphe) Raphe nucleus; (Ach) acetylcholine neurotransmitter; (NE) norepinephrine neurotransmitter; (5HT) serotonin neurotransmitter. (B) Examples of various body rhythms controlled by the SCN. Melatonin is low during the day and high at night. Corticosterone and orexin levels are coupled to the behavioral state of the animal, high during wakefulness and low during sleep. Note that the timing and shape of the waveforms are different. Distinct cell types and heterogeneity of phase within the SCN may serve to regulate the diverse timing of these targets. 
also sends projections to the lateral hypothalamus ( $\mathrm{LH}$ ) to regulate orexin secretion and cortical arousal (Fig. 9A, highlighted black). Traditionally, the ascending arousal system was thought to regulate cortical function via the neuromodulators: acetylcholine, serotonin, norepinephrin, in addition to dopamine and histamine. In 1999, a new regulatory pathway was added to the list. It was demonstrated that disruption of orexin signaling causes symptoms of narcolepsy (Chemelli et al. 1999; Lin et al. 1999). Orexins may represent a key link between SCN pacemaker function and arousal. Orexin neurons are active during waking (Bayer et al. 2004; Lee et al. 2005; Mileykovskiy et al. 2005), and there is a circadian rhythm in orexin cerebral spinal fluid levels (Fig. 9B) that is lost in SCN-lesioned animals (Deboer et al. 2004; Zhang et al. 2004).

The SCN temporally organizes processes that are associated with inactive/awake states via the orexin pathway and the corticosterone hypothalamic-adrenal axis. The SCN also temporally organizes processes that are specifically associated with the light cycle such as melatonin secretion (Fig. 9B). Thus, the SCN coordinates a number of differentially timed rhythmic events. Coordination of peripheral oscillations is achieved via distinct, identifiable output circuits that have received much research attention. Of course, to effectively coordinate differentially timed rhythms, the SCN must also receive feedback regarding the state of the various body oscillations. Feedback to the SCN is an area of research receiving more recent attention. It may well be that pathways classically described as serving "nonphotic resetting" have an important role in feedback, enabling the SCN to integrate peripheral signals, and thus promote proper organization of diverse body rhythms.

\section{ACKNOWLEDGMENTS}

We thank Drs. Marty Zatz, Doug McMahon, Mirjam Münch, and Sean Cain for comments on earlier versions of the manuscript.

\section{REFERENCES}

Abrahamson E.E. and Moore R.Y. 2001. Suprachiasmatic nucleus in the mouse: Retinal innervation, intrinsic organization and efferent projections. Brain Res. 916: 172

Albus H., Vansteensel M.J., Michel S., Block G.D., and Meijer J.H. 2005. A GABAergic mechanism is necessary for coupling dissociable ventral and dorsal regional oscillators within the circadian clock. Curr. Biol. 15: 886.

Antle M.C. and Silver R. 2005. Orchestrating time: Arrangements of the brain circadian clock. Trends Neurosci. 28: 145.

Aton S.J. and Herzog E.D. 2005. Come together, right...now: Synchronization of rhythms in a mammalian circadian clock. Neuron 48: 531.

Aton S.J., Colwell C.S., Harmar A.J., Waschek J., and Herzog E.D. 2005. Vasoactive intestinal polypeptide mediates circadian rhythmicity and synchrony in mammalian clock neurons. Nat. Neurosci. 8: 476.

Bayer L., Serafin M., Eggermann E., Saint-Mleux B., Machard D., Jones B.E., and Muhlethaler M. 2004. Exclusive postsynaptic action of hypocretin-orexin on sublayer $6 \mathrm{~b}$ cortical neurons. J. Neurosci. 24: 6760.

Beaule C., Houle L.M., and Amir S. 2003. Expression profiles of PER2 immunoreactivity within the shell and core regions of the rat suprachiasmatic nucleus: Lack of effect of photic entrainment and disruption by constant light. J. Mol. Neurosci. 21: 133.

Berson D.M. 2003. Strange vision: Ganglion cells as circadian photoreceptors. Trends Neurosci. 26: 314.

Bouskila Y. and Dudek F.E. 1995. A rapidly activating type of outward rectifier $\mathrm{K}^{+}$current and A-current in rat suprachiasmatic nucleus neurones. J. Physiol. 488: 339.

Buijs R.M. and Kalsbeek A. 2001. Hypothalamic integration of central and peripheral clocks. Nat. Rev. Neurosci. 2: 521.

Buijs R.M., Scheer F.A., Kreier F., Yi C., Bos N., Goncharuk V.D., and Kalsbeek A. 2006. Organization of circadian functions: Interaction with the body. Prog. Brain Res. 153: 341.

Chemelli R.M., Willie J.T., Sinton C.M., Elmquist J.K., Scammell T., Lee C., Richardson J.A., Williams S.C., Xiong Y., Kisanuki Y., Fitch T.E., Nakazato M., Hammer R.E., Saper C.B., and Yanagisawa M. 1999. Narcolepsy in orexin knockout mice: Molecular genetics of sleep regulation. Cell 98: 437.

Cheng M.Y., Bullock C.M., Li C., Lee A.G., Bermak J.C., Belluzzi J., Weaver D.R., Leslie F.M., and Zhou Q.Y. 2002. Prokineticin 2 transmits the behavioural circadian rhythm of the suprachiasmatic nucleus. Nature 417: 405

Coogan A.N. and Piggins H.D. 2004. MAP kinases in the mammalian circadian system: Key regulators of clock function. $J$. Neurochem. 90: 769.

Cutler D.J., Haraura M., Reed H.E., Shen S., Sheward W.J., Morrison C.F., Marston H.M., Harmar A.J., and Piggins H.D. 2003. The mouse VPAC2 receptor confers suprachiasmatic nuclei cellular rhythmicity and responsiveness to vasoactive intestinal polypeptide in vitro. Eur. J. Neurosci. 17: 197.

Damiola F., Le Minh N., Preitner N., Kornmann B., FleuryOlela F., and Schibler U. 2000. Restricted feeding uncouples circadian oscillators in peripheral tissues from the central pacemaker in the suprachiasmatic nucleus. Genes Dev. 14: 2950.

Deboer T., Vansteensel M.J., Detari L., and Meijer J.H. 2003. Sleep states alter activity of suprachiasmatic nucleus neurons. Nat. Neurosci. 6: 1086.

Deboer T., Overeem S., Visser N.A., Duindam H., Frolich M., Lammers G.J., and Meijer J.H. 2004. Convergence of circadian and sleep regulatory mechanisms on hypocretin-1. Neuroscience 129: 727.

Debruyne J.P., Weaver D.R., and S.M. Reppert. 2007. CLOCK and NPAS 2 have overlapping roles in the suprachiasmatic circadian clock. Nat. Neurosci. 10: 543.

de Jeu M., Hermes M., and Pennartz C. 1998. Circadian modulation of membrane properties in slices of rat suprachiasmatic nucleus. Neuroreport 9: 3725.

de la Iglesia H.O. and Schwartz W.J. 2006. Minireview. Timely ovulation: Circadian regulation of the female hypothalamopituitary-gonadal axis. Endocrinology 147: 1148.

Deurveilher S. and Semba K. 2005. Indirect projections from the suprachiasmatic nucleus to major arousal-promoting cell groups in rat: Implications for the circadian control of behavioural state. Neuroscience 130: 165.

Do M.T. and Bean B.P. 2003. Subthreshold sodium currents and pacemaking of subthalamic neurons: Modulation by slow inactivation. Neuron 39: 109.

Dziema H., Oatis B., Butcher G.Q., Yates R., Hoyt K.R., and Obrietan K. 2003. The ERK/MAP kinase pathway couples light to immediate-early gene expression in the suprachiasmatic nucleus. Eur. J. Neurosci. 17: 1617.

Gooley J.J., Schomer A., and Saper C.B. 2006. The dorsomedial hypothalamic nucleus is critical for the expression of foodentrainable circadian rhythms. Nat. Neurosci. 9: 398.

Green D.J. and Gillette R. 1982. Circadian rhythm of firing rate recorded from single cells in the rat suprachiasmatic brain slice. Brain Res. 245: 198.

Groos G. and Hendriks J. 1982. Circadian rhythms in electrical discharge of rat suprachiasmatic neurones recorded in vitro. Neurosci. Lett. 34: 283.

Guo H., Brewer J.M., Lehman M.N., and Bittman E.L. 2006. Suprachiasmatic regulation of circadian rhythms of gene expression in hamster peripheral organs: Effects of transplant- 
ing the pacemaker. J. Neurosci. 26: 6406.

Hausser M., Raman I.M., Otis T., Smith S.L., Nelson A., du Lac S., Loewenstein Y., Mahon S., Pennartz C., Cohen I., and Yarom Y. 2004. The beat goes on: Spontaneous firing in mammalian neuronal microcircuits. J. Neurosci. 24: 9215.

Herzog E.D., Takahashi J.S., and Block G.D. 1998. Clock controls circadian period in isolated suprachiasmatic nucleus neurons. Nat. Neurosci. 1: 708 .

Herzog E.D., Geusz M.E., Khalsa S.B., Straume M., and Block G.D. 1997. Circadian rhythms in mouse suprachiasmatic nucleus explants on multimicroelectrode plates. Brain Res. 757: 285.

Honma S., Shirakawa T., Katsuno Y., Namihira M., and Honma K. 1998. Circadian periods of single suprachiasmatic neurons in rats. Neurosci. Lett. 250: 157.

Hungs M. and Mignot E. 2001. Hypocretin/orexin, sleep and narcolepsy. Bioessays 23: 397.

Inagaki N., Honma S., Ono D., Tanahashi Y., and Honma K.-I. 2007. Separate oscillating cell groups in mouse suprachiasmatic nucleus couple photoperiodically to the onset and end of daily activity. Proc. Natl. Acad. Sci. 104: 7664.

Inouye S.T. and Kawamura H. 1979. Persistence of circadian rhythmicity in a mammalian hypothalamic "island" containing the suprachiasmatic nucleus. Proc. Natl. Acad. Sci. 76: 5962 .

1982. Characteristics of a circadian pacemaker in the suprachiasmatic nucleus. J. Comp. Physiol. 146: 153.

Itri J.N., Michel S., Vansteensel M.J., Meijer J.H., and Colwell C.S. 2005. Fast delayed rectifier potassium current is required for circadian neural activity. Nat. Neurosci. 8: 650 .

Jackson A.C., Yao G.L., and Bean B.P. 2004. Mechanism of spontaneous firing in dorsomedial suprachiasmatic nucleus neurons. J. Neurosci. 24: 7985.

Kononenko N.I. and Dudek F.E. 2006. Persistent calcium current in rat suprachiasmatic nucleus neurons. Neuroscience 138: 377 .

Kononenko N.I., Shao L.R., and Dudek F.E. 2004. Riluzole-sensitive slowly inactivating sodium current in rat suprachiasmatic nucleus neurons. J. Neurophysiol. 91: 710.

Kramer A., Yang F.C., Snodgrass P., Li X., Scammell T.E., Davis F.C., and Weitz C.J. 2001. Regulation of daily locomotor activity and sleep by hypothalamic EGF receptor signaling. Science 294: 2511.

Kuhlman S.J. and McMahon D.G. 2004. Rhythmic regulation of membrane potential and potassium current persists in SCN neurons in the absence of environmental input. Eur. J. Neurosci. 20: 1113

Kuhlman S.J., Quintero J.E., and McMahon D.G. 2000. GFP fluorescence reports Period 1 circadian gene regulation in the mammalian biological clock. Neuroreport 11: 1479.

Kuhlman S.J., Silver R., Le Sauter J., Bult-Ito A., and McMahon D.G. 2003. Phase resetting light pulses induce Per1 and persistent spike activity in a subpopulation of biological clock neurons. J. Neurosci. 23: 1441.

Lee M.G., Hassani O.K., and Jones B.E. 2005. Discharge of identified orexin/hypocretin neurons across the sleep-waking cycle. J. Neurosci. 25: 6716.

Lin L., Faraco J., Li R., Kadotani H., Rogers W., Lin X., Qiu X., de Jong P.J., Nishino S., and Mignot E. 1999. The sleep disorder canine narcolepsy is caused by a mutation in the hypocretin (orexin) receptor 2 gene. Cell 98: 365.

Liu C., Weaver D.R., Strogatz S.H., and Reppert S.M. 1997. Cellular construction of a circadian clock: Period determination in the suprachiasmatic nuclei. Cell 91: 855.

Long M.A., Jutras M.J., Connors B.W., and Burwell R.D. 2005. Electrical synapses coordinate activity in the suprachiasmatic nucleus. Nat. Neurosci. 8: 61 .

Lundkvist G.B., Kwak Y., Davis E.K., Tei H., and Block G.D. 2005. A calcium flux is required for circadian rhythm generation in mammalian pacemaker neurons. J. Neurosci. 25: 7682.

Mason R. 1991. The effects of continuous light exposure on Syrian hamster suprachiasmatic (SCN) neuronal discharge activity in vitro. Neurosci. Lett. 123: 160.

Maywood E.S., Reddy A.B., Wong G.K., O’Neill J.S., O’Brien
J.A., McMahon D.G., Harmar A.J., Okamura H., and Hastings M.H. 2006. Synchronization and maintenance of timekeeping in suprachiasmatic circadian clock cells by neuropeptidergic signaling. Curr. Biol. 16: 599.

McCormick D.A. and Huguenard J.R. 1992. A model of the electrophysiological properties of thalamocortical relay neurons. J. Neurophysiol. 68: 1384.

Meijer J.H., Watanabe K., Schaap J., Albus H., and Detari L. 1998. Light responsiveness of the suprachiasmatic nucleus: Long-term multiunit and single-unit recordings in freely moving rats. J. Neurosci. 18: 9078 .

Messager S., Ross A.W., Barrett P., and Morgan P.J. 1999. Decoding photoperiodic time through Per1 and ICER gene amplitude. Proc. Natl. Acad. Sci. 96: 9938

Michel S., Geusz M.E., Zaritsky J.J., and Block G.D. 1993. Circadian rhythm in membrane conductance expressed in isolated neurons. Science 259: 239.

Mieda M., Williams S.C., Richardson J.A., Tanaka K., and Yanagisawa M. 2006. The dorsomedial hypothalamic nucleus as a putative food-entrainable circadian pacemaker. Proc. Natl. Acad. Sci. 103: 12150.

Mikkelsen J.D. and Vrang N. 1994. A direct pretectosuprachiasmatic projection in the rat. Neuroscience 62: 497.

Mileykovskiy B.Y., Kiyashchenko L.I., and Siegel J.M. 2005. Behavioral correlates of activity in identified hypocretin/ orexin neurons. Neuron 46: 787.

Moore R.Y. 1996. Entrainment pathways and the functional organization of the circadian system. Prog. Brain Res. 111: 103.

Moore R.Y. and Eichler V.B. 1972. Loss of a circadian adrenal corticosterone rhythm following suprachiasmatic lesions in the rat. Brain Res. 42: 201.

Moore R.Y. and Speh J.C. 1993. GABA is the principal neurotransmitter of the circadian system. Neurosci. Lett. 150: 112.

Morin L.P., Shivers K.Y, Blanchard J.H., and Muscat L. 2006. Complex organization of mouse and rat suprachiasmatic nucleus. Neuroscience 137: 1285

Morse D. and Sassone-Corsi P. 2002. Time after time: Inputs to and outputs from the mammalian circadian oscillators. Trends Neurosci. 25: 632

Mrugala M., Zlomanczuk P., Jagota A., and Schwartz W.J. 2000. Rhythmic multiunit neural activity in slices of hamster suprachiasmatic nucleus reflect prior photoperiod. Am. J. Physiol. Regul. Integr. Comp. Physiol. 278: R987.

Nakamura W., Honma S., Shirakawa T., and Honma K. 2001. Regional pacemakers composed of multiple oscillator neurons in the rat suprachiasmatic nucleus. Eur. J. Neurosci. 14: 666.

2002. Clock mutation lengthens the circadian period without damping rhythms in individual SCN neurons. Nat. Neurosci. 5: 399.

Nakamura W., Yamazaki S., Takasu N.N., Mishima K., and Block G.D. 2005. Differential response of Period 1 expression within the suprachiasmatic nucleus. J. Neurosci. 25: 5481

Nelson A.B., Krispel C.M., Sekirnjak C., and du Lac S. 2003. Long-lasting increases in intrinsic excitability triggered by inhibition. Neuron 40: 609.

Nitabach M.N., Blau J., and Holmes T.C. 2002. Electrical silencing of Drosophila pacemaker neurons stops the free-running circadian clock. Cell 109: 485.

Nüsslein-Hildesheim B., O’Brien J.A., Ebling F.J., Maywood E.S., and Hastings M.H. 2000. The circadian cycle of mPER clock gene products in the suprachiasmatic nucleus of the Siberian hamster encodes both daily and seasonal time. Eur. J. Neurosci. 12: 2856.

Ohta H., Yamazaki S., and McMahon D.G. 2005. Constant light desynchronizes mammalian clock neurons. Nat. Neurosci. 8: 267.

Pennartz C.M., Bierlaagh M.A., and Geurtsen A.M. 1997. Cellular mechanisms underlying spontaneous firing in rat suprachiasmatic nucleus: Involvement of a slowly inactivating component of sodium current. J. Neurophysiol. 78: 1811.

Pennartz C.M., de Jeu M.T., Bos N.P., Schaap J., and Geurtsen 
A.M. 2002. Diurnal modulation of pacemaker potentials and calcium current in the mammalian circadian clock. Nature 416: 286.

Quintero J.E., Kuhlman S.J., and McMahon D.G. 2003. The biological clock nucleus: A multiphasic oscillator network regulated by light. J. Neurosci. 23: 8070 .

Ralph M.R., Foster R.G., Davis F.C., and Menaker M. 1990. Transplanted suprachiasmatic nucleus determines circadian period. Science 247: 975.

Raman I.M., Gustafson A.E., and Padgett D. 2000. Ionic currents and spontaneous firing in neurons isolated from the cerebellar nuclei. J. Neurosci. 20: 9004.

Refinetti R., Kaufman C.M., and Menaker M. 1994. Complete suprachiasmatic lesions eliminate circadian rhythmicity of body temperature and locomotor activity in golden hamsters. J. Comp. Physiol. A 175: 223.

Rutter J., Reick M., and McKnight S.L. 2002. Metabolism and the control of circadian rhythms. Annu. Rev. Biochem. 71: 307.

Rutter J., Reick M., Wu L.C., and McKnight S.L. 2001. Regulation of clock and NPAS2 DNA binding by the redox state of NAD cofactors. Science 293: 510.

Saper C.B., Scammell T.E., and Lu J. 2005. Hypothalamic regulation of sleep and circadian rhythms. Nature 437: 1257.

Schaap J., Albus H., VanderLeest H.T., Eilers P.H., Detari L., and Meijer J.H. 2003. Heterogeneity of rhythmic suprachiasmatic nucleus neurons: Implications for circadian waveform and photoperiodic encoding. Proc. Natl. Acad. Sci. 100: 15994.

Schaap J., Bos N.P., de Jeu M.T., Geurtsen A.M., Meijer J.H., and Pennartz C.M. 1999. Neurons of the rat suprachiasmatic nucleus show a circadian rhythm in membrane properties that is lost during prolonged whole-cell recording. Brain Res. 815: 154.

Schwartz W.J. and Gainer H. 1977. Suprachiasmatic nucleus: Use of 14C-labeled deoxyglucose uptake as a functional marker. Science 197: 1089.

Schwartz W.J., Gross R.A., and Morton M.T. 1987. The suprachiasmatic nuclei contain a tetrodotoxin-resistant circadian pacemaker. Proc. Natl. Acad. Sci. 84: 1694.

Shibata S., Liou S., Ueki S., and Oomura Y. 1984. Influence of environmental light-dark cycle and enucleation on activity of suprachiasmatic neurons in slice preparations. Brain Res. 302: 75 .

Shibata S., Oomura Y., Kita H., and Hattori K. 1982. Circadian rhythmic changes of neuronal activity in the suprachiasmatic nucleus of the rat hypothalamic slice. Brain Res. 247: 154.

Silver R., LeSauter J., Tresco P.A., and Lehman M.N. 1996. A diffusible coupling signal from the transplanted suprachiasmatic nucleus controlling circadian locomotor rhythms. Nature 382: 810

Smith S.L. and Otis T.S. 2003. Persistent changes in spontaneous firing of Purkinje neurons triggered by the nitric oxide signaling cascade. J. Neurosci. 23: 367.

Stephan F.K. and Zucker I. 1972. Circadian rhythms in drinking behavior and locomotor activity of rats are eliminated by hypothalamic lesions. Proc. Natl. Acad. Sci. 69: 1583.

Stokkan K.A., Yamazaki S., Tei H., Sakaki Y., and Menaker M. 2001. Entrainment of the circadian clock in the liver by feeding. Science 291: 490.

Stoleru D., Peng Y., Nawathean P., and Rosbash M. 2005. A resetting signal between Drosophila pacemakers synchronizes morning and evening activity. Nature 438: 238.

Stoleru D., Nawathean P., Fernandez M.P., Menet J.S., Ceriani M.F., and Rosbash M. 2007. The Drosophila circadian network is a seasonal timer. Cell 129: 207.

Stratmann M. and Schibler U. 2006. Properties, entrainment, and physiological functions of mammalian peripheral oscillators. J. Biol. Rhythms 21: 494.

Strecker G.J., Wuarin J.P., and Dudek F.E. 1997. GABA A-medi- $^{-}$ ated local synaptic pathways connect neurons in the rat suprachiasmatic nucleus. J. Neurophysiol. 78: 2217.

Sudo M., Sasahara K., Moriya T., Akiyama M., Hamada T., and Shibata S. 2003. Constant light housing attenuates circadian rhythms of mPer2 mRNA and mPER2 protein expression in the suprachiasmatic nucleus of mice. Neuroscience 121: 493.

Sumova A., Jac M., Sladek M., Sauman I., and Illnerova H. 2003. Clock gene daily profiles and their phase relationship in the rat suprachiasmatic nucleus are affected by photoperiod. $J$. Biol. Rhythms 18: 134.

Sumova A., Travnickova Z., Peters R., Schwartz W.J., and Illnerova H. 1995. The rat suprachiasmatic nucleus is a clock for all seasons. Proc. Natl. Acad. Sci. 92: 7754.

Taddese A. and Bean B.P. 2002. Subthreshold sodium current from rapidly inactivating sodium channels drives spontaneous firing of tuberomammillary neurons. Neuron 33: 587.

VanderLeest H.T., Houben T., Michel S., Deboer T., Albus H., Vansteensel M.J., Block G.D., and Meijer J.H. 2007. Seasonal encoding by the circadian pacemaker of the SCN. Curr. Biol. 17: 468 .

Vansteensel M.J., Yamazaki S., Albus H., Deboer T., Block G.D., and Meijer J.H. 2003. Dissociation between circadian Per1 and neuronal and behavioral rhythms following a shifted environmental cycle. Curr. Biol. 13: 1538.

Vitaterna M.H., King D.P., Chang A.M., Kornhauser J.M., Lowrey P.L., McDonald J.D., Dove W.F., Pinto L.H., Turek F.W., and Takahashi J.S. 1994. Mutagenesis and mapping of a mouse gene, Clock, essential for circadian behavior. Science 264: 719 .

Welsh D.K., Logothetis D.E., Meister M., and Reppert S.E. 1995. Individual neurons dissociated from rat suprachiasmatic nucleus express independently phased circadian firing rhythms. Neuron 14: 697.

Wilsbacher L.D., Yamazaki S., Herzog E.D., Song E.J., Radcliffe L.A., Abe M., Block G., Spitznagel E., Menaker M., and Takahashi J.S. 2002. Photic and circadian expression of luciferase in mPeriod1-luc transgenic mice in vivo. Proc. Natl. Acad. Sci. 99: 489.

Yamaguchi S., Isejima H., Matsuo T., Okura R., Yagita K., Kobayashi M., and Okamura H. 2003. Synchronization of cellular clocks in the suprachiasmatic nucleus. Science 302: 1408 .

Yamaguchi S., Kobayashi M., Mitsui S., Ishida Y., van der Horst G.T.J., Suzuki M., Shibata S., and Okamura H. 2001. View of a mouse clock gene ticking. Nature 409: 684.

Yamazaki S., Numano R., Abe M., Hida A., Takahashi R., Ueda M., Block G.D., Sakaki Y., Menaker M., and Tei H. 2000. Resetting central and peripheral circadian oscillators in transgenic rats. Science 288: 682.

Yan L., Takekida S., Shigeyoshi Y., and Okamura H. 1999. Per1 and Per2 gene expression in the rat suprachiasmatic nucleus: Circadian profile and the compartment-specific response to light. Neuroscience 94: 141.

Yoo S.H., Yamazaki S., Lowrey P.L., Shimomura K., Ko C.H., Buhr E.D., Siepka S.M., Hong H.K., Oh W.J., Yoo O.J., Menaker M., and Takahashi J.S. 2004. PERIOD2::LUCIFERASE real-time reporting of circadian dynamics reveals persistent circadian oscillations in mouse peripheral tissues. Proc. Natl. Acad. Sci. 101: 5339

Zhang S., Zeitzer J.M., Yoshida Y., Wisor J.P., Nishino S., Edgar D.M., and Mignot E. 2004. Lesions of the suprachiasmatic nucleus eliminate the daily rhythm of hypocretin-1 release. Sleep 27: 619 . 


\section{$8_{\mathrm{CSH}}^{\infty} \mathrm{C}$ Cold Spring Harbor Symposia SYMPOSIA on Quantitative Biology}

\section{Biological Rhythms Workshop IB: Neurophysiology of SCN Pacemaker Function}

\section{S. J. Kuhlman}

Cold Spring Harb Symp Quant Biol 2007 72: 21-33

Access the most recent version at doi:10.1101/sqb.2007.72.061

References This article cites 109 articles, 32 of which can be accessed free at:

http://symposium.cshlp.org/content/72/21.full.html\#ref-list-1

\section{License}

Email Alerting Service
Receive free email alerts when new articles cite this article - sign up in the box at the top right corner of the article or click here. 